\title{
Agency and intermediate phase writing in a farm school
}

\author{
Author: \\ Margaret A. Hill ${ }^{1}$ \\ Affiliation: \\ ${ }^{1}$ Education and Social \\ Sciences, Cape Peninsula \\ University of Technology, \\ South Africa \\ Correspondence to: \\ Margaret Hill \\ Email: \\ able2readwrite@gmail.com \\ Postal address: \\ 72 Main Road, Greyton 7233, \\ South Africa \\ Dates: \\ Received: 17 Sept. 2014 \\ Accepted: 09 Mar. 2015 \\ Published: 17 June 2015 \\ How to cite this article: \\ Hill, M.A., 'Agency and \\ intermediate phase writing \\ in a farm school', Reading \\ \& Writing 6(1), Art. \#59, \\ 8 pages. http://dx.doi \\ org/10.4102/rw.v6i1.59

\section{Copyright:} \\ (C) 2015. The Authors. \\ Licensee: AOSIS \\ OpenJournals. This work is \\ licensed under the Creative \\ Commons Attribution \\ License.
}

Against a background that raises problems associated with the classification of languages in current South African curriculum policy, this article describes a programme based on a visual approach to writing, implemented in a farm school. The medium of instruction was English. The home languages of the teachers and learners were Afrikaans and isiXhosa. Sociocultural perspectives congruent with those of New Literacy Studies influenced the design of the writing programme. The school management had identified a serious deficit in intermediate phase (Grades 4-6) learners' ability to perform beyond typical responses to rote learning. The brief given to the literacy coach by the school management was to develop their ability to use English - the language of learning and teaching (LoLT) of the school - expressively, to help them to construct original texts and to improve their mastery of the conventions of text. The management's main aim was to promote the learners' agency in their use of English, as it had come to see this ability as crucial to academic progress in higher Grades and to success in tertiary education. The literacy coach implemented a visual approach to composing original texts. Key successes were evident in the variety, volume and literary quality of the learners' texts, which exceeded expectations specified in the National Curriculum Statement applicable at the time.

\section{Introduction}

Transnational tests have revealed weaknesses in South African children's performance in literacy, especially in their ability to originate and comprehend meaning in their language of learning and teaching (LoLT). This project contributes to discussions on pedagogies that may be effective in addressing these weaknesses.

The first part of this article raises problems associated with the classification of languages in South Africa in shaping the language curriculum, their effects on identity and agency, and how these effects may constrain or promote learning.

The second part describes a writing project in a rural school where children were expected to achieve expressive agency in their use of English, which was not the 'home language' of learners or teachers.

\section{Background: The language of learning and teaching Framing the 'LoLT'}

One of the more curious acronyms in current literacy discourse in South Africa is the 'LoLT'. Short for 'language of learning and teaching', the acronym occupies an ambivalent position between a conception of a hegemonic language, usually English, as imperialistic, and a view of English as an empowering tool of communication because it is particularly susceptible to shifting, hybridising pressures that make it a medium for fluid inter-, trans- and even supra-cultural discursive exchanges that pose little threat of domination (Canagarajah 1999).

For those who subscribe to the view that a language inherently carries an imperialist intentionality, the semiotics of the term LoLT suggest that such intentionality can be ameliorated by relegating it to particular purposes and contexts, so avoiding the risk of 'colonising' the user's mind (Ngugi wa Thiong'o 1986:9). Furthermore, any language that is used as the all-purpose medium of instruction in a school can be called a LoLT, which implies that the utility of languages for schooling makes them potentially 'equal' in status and effect. The gloss of instrumentality that the term confers on a language implies that it can be deployed or resisted dispassionately, thereby constraining cultural contamination of the user's identity.

The limitations of this utilitarian understanding of 'the LoLT' come to the fore when constructivists consider how children learn. A constructivist orientation sees affective engagement and agency 
as symptomatic of effective learning, mediated by social interaction and trust (Moll \& Whitmore in Foreman et al. 1993:28). Emotion and relationships, therefore, drive learning (Guthrie \& Klauda 2013, n.p.). Children of bilingual families demonstrate that given conducive social, instructional and affective conditions, they are capable of mastering more than one language simultaneously (Akbulut 2007) with scant regard for the proper purposes and status to which each should be attributed in their lives, but firmly rooted in the contexts of their use and the qualities of the interlocutors' relationships.

Krashen's (1982:30-32) theory with regard to the affective filter implies that how learners relate to the acquisition of an additional language can constrain agency, or self-efficacy, in engaging with the language expressively. Engagement is an effect of intrinsic motivation, which in turn is an effect of an agentic sense of self, or identity. This begs profound questions. Is it conceivable that the notion of the LoLT as essentially foreign, and as having a limited, instrumental status, could exclude matters of heart and mind for learners, in other words - identity, and that this sense of alienation might inhibit a child's meaning-making capacity in the language of learning?

At present, it appears that language policy in South Africa is wrestling with tensions generated by a hierarchical view of the statuses of languages that tends to feed the imperialist thesis. For schooling purposes, languages are ranked in a perceived lineal order of their acquisition from which assumptions about learners' competence are derived: Home Language, First Additional, Second Additional, and so on. The policy assumes that home language delivers a vital initial generic foundation in vocabulary, basic concepts, thinking tools, aesthetic experience, social and moral values and identity formation that can facilitate acquisition of an additional language at a level of complexity suitable for success in schooling. There is, however, evidence in some South African studies that learners' literacy in their home language is not a consistent indicator of better academic performance than their literacy in a first additional language $\left(\right.$ FAL) ${ }^{1}$ (Howie et al. 2012:39; 43). A linear hierarchical view of languages 'for learning' does not seem helpful in explaining this phenomenon.

In questioning the validity of the terms 'native' and 'nonnative' speakers, and 'mother tongue' in a multilingual, globalising environment, Chimbganda (2005:19-22) subverts the imperialist thesis, and by extension any attempts to assign status to languages based on the perceived culture of users, to open the debate to the notion that 'the purpose of any language is to act as a tool of thought' (29), thereby making the agency of the user the arbiter of a language's classification.

New Literacy Studies (NLS) offers an alternative view of languages as socially situated practices, and children's texts

1.'FAL' is a term synonymous in South Africa with $\mathrm{L} 2$. as traces of literacy practices happening in various sites and drawn from multiple domains of life (Pahl 2007). According to this view, language use is fluid, depending on the situated demands of participation in particular places and times, and takes account of out-of-school language experiences that children bring to bear on discursive events in school. In other words, this view lends itself to sociocultural approaches to literacy pedagogy.

The LoLT then can be seen less as a slightly weakened, default toolkit to the home language, and more as the 'home language' of a particular discursive moment. Framed in this way, teachers would look for opportunities for learners to deploy and extend a range of perceptual and linguistic abilities drawn from their multilingual experiences in discursive events in and out-of-school, in a number of language codes in their repertoires. Academic discourse could develop independently of the home language (Collier \& Thomas 2004:2). It is possible that concepts constructed in the language of a particular event would not have to be filtered through the home language to be understood and used. In this scenario, the culturally bound, hierarchical status of a language as an organising principle in curriculum design would cease to exist, and expectations of performance in any language curriculum in a school would have no limit. For learners, a language's 'status' would describe their competence to deploy it at will to communicate meaning in discursive contexts, rather than on the education system's perception of their likely 'home languages' tied to ethnicity or cultural allegiances.

\section{The 'LoLT': Assessment and progression}

Currently, the management principle of language programmes is determined by hierarchical preconceptions of cultural allegiances tied to language and ethnicity, rather than by unrestricted access determined by a user's agentic choices and competence. This principle imposes a regimen that may disrupt and obscure a learner's authentic language development and consequent learning capacity in school. For example, an isiXhosa speaker in an English-as-LoLT school environment could find herself being assessed in English as 'Home' language, Afrikaans as 'First Additional Language' (FAL) and isiXhosa, the learner's home language, as 'Second Additional Language'. Alternatively, a learner in an Englishas-LoLT, but 'FAL' environment actually dominated by, for example, learners and teachers who are native isiXhosa or Afrikaans speakers, may not be exposed to the aesthetic and conceptual challenges in English that learning requires, and could be falsely led to expect success in a tertiary environment that actually requires a level of competence that challenges even native speakers of English.

Whilst it may suit policy makers to believe that a home language speaker who has mastered concepts necessary for academic success can switch languages and perform to potential within the normal time frames allowed for progression in schooling and tertiary programmes, this rarely happens. In a large scale longitudinal study of English 
language learners' (ELLS') performance in the United States, Collier and Thomas (2004:5) are critical of the assumption in federal legislation that E.L.L.s should be on grade level in three years and 'consistently found that it takes six to eight years, for ELLs to reach grade level in [second language] L2'. Authentic evaluation therefore should assess in which language(s) the learner has actually achieved the competences that indicate potential for progression, and the gap that has to be closed between learners' performance in their 'native' language and the required grade level performance in the LoLT. Given the length of time it takes for learners to close the gap between native and non-native speakers of the LoLT, it seems reasonable to assume that learners should be enabled to aim for parity in performance between languages as early as possible. Collier and Thomas (2004:2) imply that there simply is not enough time for 'remedial' programmes, which they characterise as "programs [sic] that offer "watered down" instruction in a "special" curriculum that focussed on one small step at a time' and describe the characteristic features of an alternative effective pedagogy:

Teachers in these bilingual classes create the cognitive challenge through thematic units of the core curriculum, focused on real world problem solving, that stimulate students to make more than one year's progress every year, in both languages. With no translation and no repeated lessons in the other language, separation of the languages is a key component of this model. Peer teaching and teachers using cooperative learning strategies to capitalize on this effect serve as an important stimulus for the cognitive challenge. (p. 2; author's emphasis)

This model of a parallel bilingual curriculum would require differentiated teaching and assessment, and social constructivist practices that rely heavily on formative evaluation and mediation. The provision of sufficient competent teachers for each of the languages offered in a particular region or school would become imperatives of curriculum management. South African policy appears to endorse these practices: '[Teachers] can provide feedback that enables learners to get a sense of their own strengths and weaknesses and an understanding of how to move forward' (Department of Basic Education 2011:6).

Differentiated teaching means using open-ended, multilevel processes, and assessment that is diagnostic rather than normreferenced. Teachers would have to be confident in managing diversity, and in recognising the pedagogical value of peer teaching characteristic of classrooms where communicative interactions between learners is encouraged. The ultimate goal of this approach to language would be to enable learners to operate in an English academic environment with the facility and self-efficacy of 'home' language speakers, because that is what is currently necessary to engage in national and global academic and economic discourses.

Most South African children face the challenge of being educated in a language that is not their mother-tongue and in which they will have to engage in tertiary education and the economy. In order to succeed, learners need to be comfortable using English to originate meaning beyond the duration of specific pedagogic actions. In other words, they need to be agentic, and not merely reactive or passive, in their use of English. Bourdieu and Passeron (1990:31-33) point out that pedagogic action that results in 'durable training' is a long process of internalisation by the learner, so that the language becomes a 'habitus' ${ }^{2}$ for the learner. How then, do educators inculcate durable conceptual and creative ability in an acquired language, English, so that it becomes a generative habitus for learners? This means that if agency is truly both method and outcome of a long process of internalisation, then time is a crucial resource required for effective pedagogical action.

\section{A sociocultural writing project in a rural school}

The second part of this article describes a writing project featuring social constructivist practices, that I conducted in a rural setting to address the challenge of helping children to achieve agency and fluency, with engagement, in their use of their 'LoLT', English. The brief given to me as literacy coach was to help the children in the intermediate phase (IP) ${ }^{3}$ of the general education and training band (GET) ${ }^{4}$ to write expressively and construct original meaning in English.

\section{The writing project site}

The site of the project was a farm school of approximately 200 learners located in the northern Karoo on a minor gravel road 35 kilometres from the nearest small town. The school comprised a preschool class from age three to reception year (Grade R), and Grades 1-9 in monograde classes. The school's priority was to provide quality education for farm and casual workers' children, some of whom were from migrant karretjie $^{5}$ families. Spare places were taken by children from the town who travelled out to school daily in a 60-seat bus. The number of 'town children' admitted to the school was therefore circumscribed by the number of seats available on the bus. A fair proportion of the town children were middle class and bilingual, in Afrikaans or isiXhosa, and English. None of the teachers in the intermediate phase spoke English as a home language. Class sizes in the intermediate phase ranged from 15-20.

By the time I introduced the project, the language policy of the school specified English as the medium of instruction in the school, a decision reached after more than a decade of implementing mother-tongue isiXhosa ('home language') literacy in Grades 1-3 before transitioning to English in Grade 4. In fact, there were at least three other mothertongue groups of learners in the school, namely Afrikaans,

2. The habitus is therefore a generative rather than a fixed system: a basis from which endless improvisations can derive; a "practical mastery" of skills, routines, aptitudes and assumptions which leave the individual free to make (albeit limited) choices in the encounter with new environments or fields' (http://faculty.washington.edu/ cbehler/glossary/habitus.html).

3.Grades 4-6

4.Grades 1-9.

5.Karretjie means 'little cart' and refers to the donkey carts that migrant families use to move their families and shelters in pursuit of casual work on farms. 
Sesotho and Setswana speakers. This diversity complicated the school's language policy as it was not possible to accommodate all the home languages in the curriculum.

In an interview, the programme director (pers. comm.) gave me an overview of efforts to prepare children for the switch to English in Grade 4, using the Molteno Breakthrough to Literacy mother-tongue methodology for Grades 1-3, and bridging to English in Grade 4 (P. Lubbe for the Molteno Project 2000, 2004). The methodology had worked well for mother-tongue isiXhosa literacy in the early grades, except that there was insufficient available reading material. The transition to English in Grade 4, however, was a major setback for the children. Nevertheless, the Molteno approach to mother-tongue literacy continued to be used for five years, supplemented by READ materials and workshops, until the school management, with the support of the parents, decided to switch to a Molteno Breakthrough programme for English mother-tongue children to accelerate acquisition of English.

During workshops to train teachers at the school for the Revised National Curriculum Statement (RNCS) Dr Louis Benjamin found that the children in Grades 1-3 had serious language problems, probably due to gaps in basic concepts that should have been established in Grade R. He conducted baseline tests and introduced basic concepts, phonics and thematically based vocabulary programmes in Grades R-3 (Benjamin 2006). Basic concepts were introduced in the home languages (isiXhosa and Afrikaans) in Grade R, and repeated in Grades 1-2 in English. A key feature of this programme was that children were encouraged from the beginning of their acquisition process to speak in full sentences.

Nevertheless, the programme director noted that in spite of the remarkable improvement in mastery of basic concepts in the foundation phase, there were still conceptual gaps in Grades 4-6 the intermediate phase - that manifested in the children's inability to put their own thoughts into writing in English. The project in the intermediate phase was intended to build on the basic concepts and vocabulary developed in the foundation phase in order to develop learners' ability to write original text. The children had not attempted to originate their own text during the foundation phase, but had written sentences related to the planned themes with the teachers' guidance.

\section{A visual approach to literacy}

During a visit to the United States I attended a presentation of a visual art-based book writing project by Prof Beth Olshansky (2007) and immediately recognised her approach's potential for the farm children. She had developed a twostream process that combined art making with the more widely practised writers' workshop approach. Children became both 'artists and writers' (Olshansky 2008) of real books. The teacher supported the writing process by reading selected picture books that modelled art techniques and text features that were discussed by the children in their roles as artists and writers.

Prewriting visualisation is widely accepted and encouraged as a feature of emergent writing in the foundation phase (Wiley, cited in Scharer \& Pinell 2008), but is rare in school past Grade 3. Prewriting visualisation should not be confused with illustrating a text after it has been written. The advantages for language learners of being given the opportunity to originate meaning visually first are obvious: visual perception does not require prior mastery of a symbolic system to compose a text.

The programme I implemented was derived from this Picturingwriting (Olshansky 2008) process.

\section{Professional support}

I worked in the school in week-long sessions three times a year over three years. The mornings were spent in the classrooms with the teachers, demonstrating and coteaching an art-based workshop approach to writing, and assisting in reading aloud, guided reading, art-making and word study. Workshops with the teachers were held after school, during which the principles and processes of new methods were explained, discussed and debated. Scrutiny of the work produced by the children guided planning successive phases of the writing workshops. Differentiated teaching was an inherent feature of the workshop format.

The school had an extensive library of approximately 10000 items. Teachers were encouraged to draw selections of books from the library for their classrooms and change the selections regularly. In addition, they had sets of graded readers and at least three different dictionaries or thesauruses available for children to use in the classroom.

Coaching in the use of 'Reading half-hour' every day as an essential element of the programme, took various forms in the classrooms with the teachers: reading aloud, silent independent reading, guided reading to assist slower readers, 'acting out' stories and word study. Children became familiar with narrative structures when stories were read aloud to them and discussed in terms of their settings, characters, problem, how the story 'worked out' and the children's affective responses. For example, Niki Daly's (1999, 2003a) Jamela stories were used to model a plot based on a problem or crisis. Once upon a time (Daly 2003b) modelled a quest for achieving a goal. The children rapidly learned to analyse various genres of fiction in terms of their structures.

\section{Preparation for book writing}

During self-selected silent reading children were encouraged to tip-toe to the blackboard and contribute interesting words to a list. Towards the end of the session the contributors were asked to read their words to the class, explain their meanings, and why they liked them. The children could write words they found interesting from the list into their personal 


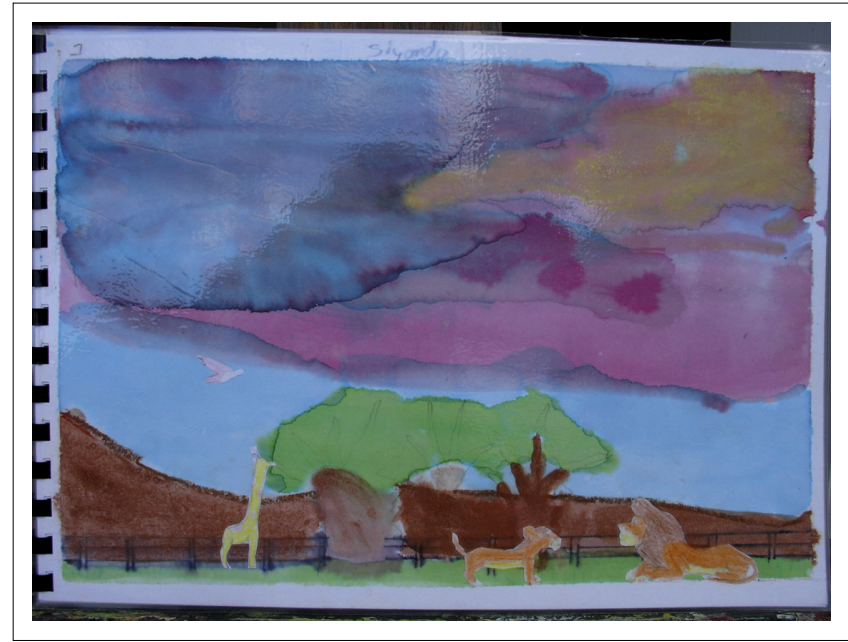

Source: Picture provided by author

FIGURE 1: Siyanda's picture.

dictionaries. The lists grew rapidly, and included words like 'squiggle' and 'commotion'. This practice expanded children's vocabularies and sparked interest in words as discrete phenomena. The thesaurus was a popular resource. Some of the words the children found most attractive were incorporated into the weekly spelling programme.

Art-making became important. In afternoon sessions teachers experimented with various media and techniques that the children used later in their illustrations: wax pastels for vivid colour; wax crayon resist and colour washes; frottage; and collage. An example of the impact of the art making on the children's engagement and expression is evident in Figure 1, The Brave Lion, a freely adapted retelling of The Lion King: 'In those days, flamingoes [sic] flew in the African skies that turn into wonderful paints which look as if they were thrown from heaven to earth' (Siyanda, Grade 6).

A further noteworthy feature of Siyanda's story is the imaginative integration of traces from other curriculum subjects and awareness of global events in the names he attributes to characters:

'Nairobi saved his son from the claws of death while the sun was still blazing with fire. Nairobi slipped while saving his son. Kampala screamed, 'No!' When he saw his father climbing up, his heart was relieved. As he was about to fall, another male lion came to their rescue. It was Obama! He saved Nairobi and ran'. (Siyanda, Grade 6)

In his biographical note, a feature of the books that was particularly revealing about the quality of the children's engagement, Siyanda, writes as follows:

'... I love to eat macaroni and cheese. I love to play soccer and cricket. My home language is Xhosa and I can also speak English and Afrikaans. I really enjoyed making this book because I could use my imagination'. (Siyanda, Grade 6)

The child responds holistically to his delight in his creativity, conflating sensory experience and pride in his multilingualism in an affirmation of his agency.

\section{Social construction of 'word boxes'}

In initial exercises, the children practised the visual approach to finding vocabulary to capture images they produced by going outside, selecting a view using a paper frame and in a group with peers, discussing what they saw in their frame in terms of basic concepts - colours, shapes, scale and distance. They generated similes and metaphors to describe sensory experiences like sounds and textures. They returned to the classroom and drew their pictures from memory. Using a tabular template - 'word box' - the group took turns to display their pictures to each other and generate words to describe the images. The teacher encouraged them to use figures of speech, which elicited sentences like 'There were mountains which look [sic] like a tortoise shell and like a table' (Taznia, Grade 4), and 'One windy day in the karoo [sic] the windmill was crying of loneliness' (Sinawe, Grade 5).

In most cases, the word box exercise generated animated and focussed group interaction in finding words together and elicited a flow of sentence making that went beyond the few lines on the template, spilling on to the other side of the page. The children then displayed their pictures, and read the sentences they had composed, to their peers' enthusiastic applause. Crucial to the success of these exercises was the development of a facilitative intersubjective attitude (Palinscar 1998:355) as part of the classroom culture, demonstrated by the recognition and encouragement the children gave each other as they collaborated in constructing the meaning of words and sharing sentences.

\section{Authors and illustrators: The workshop approach}

Before the book writing process commenced, I explained that we were going to publish books worthy of inclusion in the library, that is, the children were real authors and illustrators and would go through the process of drafting, revising and editing until they produced a perfect manuscript for the publisher, their teacher.

Each author was given a large envelope for storing drafts and pictures between workshop sessions. Drafts were revised in class, whilst the teacher and I circulated, conferencing with individuals and mediating to resolve problems or teach skills (e.g. how to use a dictionary or thesaurus). The teachers would type the final corrected drafts of the Grades 4-5 authors into their computers, and the Grade 6 authors would enter their drafts themselves. Books had to have cover pages, dedications and biographical notes featuring the author-illustrators. These high expectations generated excitement as we looked at these text features in trade books.

Phase 1 of the drafting process was generating storyboards. The children displayed their storyboards to the class, and told their stories orally. Their peers asked the authors questions that helped them to clarify gaps in dialogue, sequence of events and solutions to their plots, after which the drawings could be revised. 


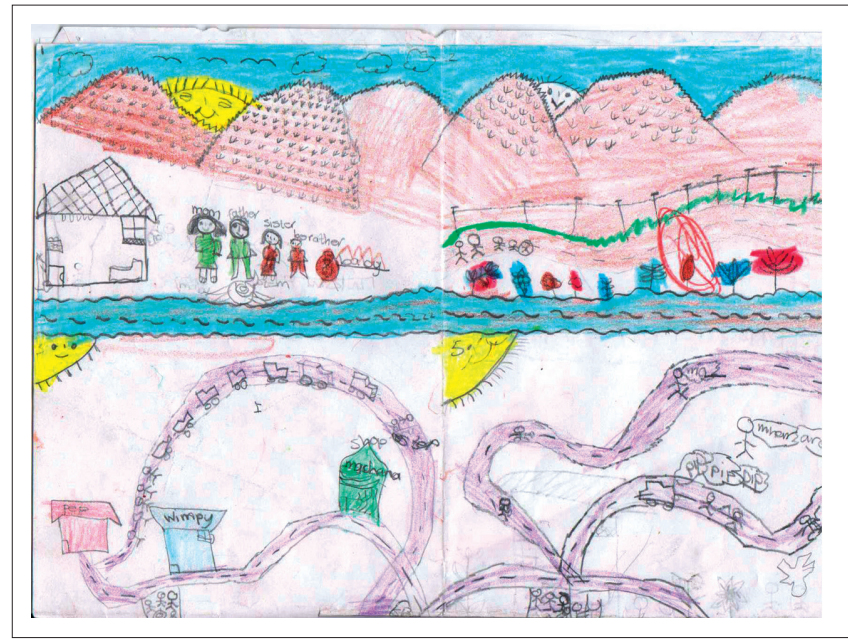

Source: Picture provided by author

FIGURE 2: Thinking visually: Frames 1-4 of Sikelewa's storyboard.

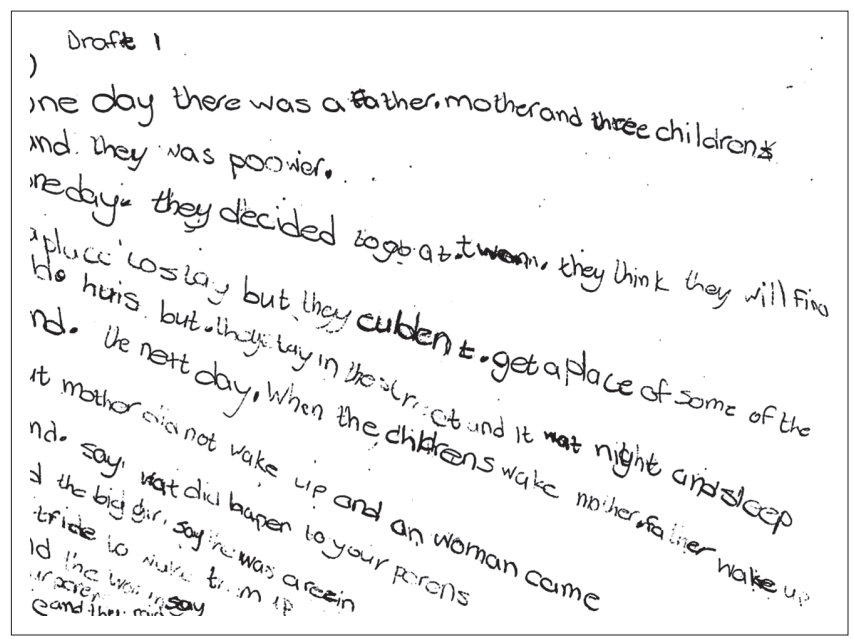

Source: Picture provided by author.

FIGURE 3: Sikelelwa's first draft.

The evolution of Sikelelwa's (Grade 4, age 10) book illustrates the process (Figure 2).

In Phase 2, each thumbnail was redrawn to fit an A4 page. Parallel to the enlargement of pictures, text was generated for each picture, until the author had produced a first draft of the whole story. Further development of the story happened in the redrawing of the pictures.

There were three handwritten drafts of the text in Sikelelwa's envelope. In the first draft (Figure 1), Sikelewa's struggle to write down the tragic burden of her thoughts is evident in her use of punctuation. A period traces moments of hesitation in her thinking process. Each successive draft is richer in detail as her confidence as a storyteller grows, and with the mediation of her teacher, more refined in its structure and improved in its spelling, syntax, punctuation and handwriting:

'Draft 1 (Figure 3): One day there was a father. mother and three childrens and they was poower. One day. they decided to go at. twon. they think they will find a place to stay but they culdent. get a place of some of the old. Huis but. they stay in the street and it wat night and sleep and. the next day. when the childrens wake mother. father wake up but mother did not wake up and an woman came and. say wat did happen to your parens and the big girl say the was arizen I tride to wake them up and the woman say your parens die and they craid'. (Sikelewa, Grade 4)

Sikelelwa, who lived on a farm, was described by her teacher as 'a dreamer' who tended to underperform. The final version of her story however, has extraordinary depth of insight into the family's poverty, and empathy with the characters who survive the tragedy. Literary elements of suspense, foreshadowing and the influence of fairy tale endings emerge in the text:

\section{Finding a better life by Sikelelwa (Grade 4, age 10)}

One day there was a father and mother and three children. They were very poor. The roof of their house was covered with grass and had holes and cracks in it. They didn't have money to buy food or furniture. The only food they had was soup made of green leaves they found in the field.

The family decided to look for a better life in town. They walked all along the gravel road.

They arrived in town at sunset. They were very tired of walking the whole day and the children were crying because they were hungry. The parents gave their children the last food they had.

They had no place to sleep so they slept on the pavement that night. The parents threw their only blanket over the children. They felt weak because they haven't [sic] eaten for a while. They gave all of the food to their children the last few days.

The children woke up the next morning. They tried to wake their parents but nothing happened. A woman who walked by asked them what was going on. The eldest daughter told her that her parents wouldn't wake up. When the woman looked closer she found that both the parents had died during the night. The children cried.

The woman who found them on the street arranged the parents' funeral. She gave the children neat clothes to wear that day. They were all crying because they were sad and didn't know what was going to happen to them.

But the woman who found them on the street was a kind and rich lady. She didn't have children of her own. She lived in a big house with lots of beautiful furniture.

The lady took the children to her house. She told them that they could stay with her. The children got their own room with soft and warm blankets on their beds. They would never be hungry again. The children missed their parents a lot, but they lived happily ever after with the kind lady.

The oral dimension of the book writing played a significant part in developing the fluency of the text in the final version. It was in the communication of the text to an audience of peers that the writers experienced their cryptic gaps and syntactical faults. They often corrected these spontaneously during their performances, a practice that spurred selfcorrection and enhanced self-efficacy. The effect on the children's sense of self when they observed a peer reading their books aloud was inestimable. 


\section{Mediation style}

Sensitive mediation was crucial to the success of the project in establishing the children's agency as writers. It was vital that the teacher refrain from rewriting the text for the authors. Teachers were encouraged to use a conferring protocol (Calkins, Hartman \& White 2005) when interacting with writers, which adhered to a sequence of four kinds of actions whilst the children were revising their drafts in class:

- ask the learner what he or she needs or wants to do ('research')

- select an appropriate teaching strategy ('decide')

- mediate ('teach')

- link the learning to the learner's past experience and future performance.

When teachers found that a large proportion of children needed to be taught a particular skill, for example, the punctuation of direct speech, they stopped the process to give a mini-lesson to the whole class, focussed on the target skill. This constructivist practice provided reference points when conferring one-on-one: 'Remember when we ...?'

From the evidence of 'red pen' in the drafts I deduced that the teachers had used the protocol with varied success. The less the teachers rewrote for the writers in successive drafts, the more successful the mediation by means of conferring was seen to be. Sets of stories where there had been denser rewriting tended to be more similar in tone than sets where there had been more conferring and less 'marking'. The challenge for the teachers was time. It was difficult for them to restrain their inclination to 'fix' flaws because the processes of self-correction were slow compared with conventional 'marking' and copying of corrections, especially for the Grade 6 teacher who was teaching separate subjects across grades, and therefore could not use time as flexibly as the teachers delivering the whole curriculum.

\section{Results}

Given the brief to develop agency in the learners' use of English, indications of success would include variety and uniqueness, expressive use of language, and extended text.

The children produced 94 texts in a range of narrative genres including fantasy (mainly anthropomorphic stories influenced by elements of fables and folktales) and realism that included memoir, themes of crime, poverty, friendship and cultural symbolism. Each story was unique. Whilst the learners' texts conformed to conventional structures of narrative structure - character, setting, problem, plot, resolution and theme - each maintained its personal vision and expressive style. It appears that the opportunity to create and revise characters and settings visually, enabled the writers to play imaginatively with the images, the essence of play being the agent's freedom to initiate 'something new', so that 'all sorts of things seem possible; things can become different from "the way they are"' (Greene 1988:48).
TABLE 1: Text length stipulated in the curriculum (National Curriculum Statement). Essay 100-120 words 120-140 words 140-150 words Short story (inc. folktale) $\quad 120-140$ words $\quad 140-160$ words $\quad 160-170$ words Source: Department of Basic Education, 2011, Curriculum and assessment policy statement grades 4-6: English Home Language, Government Printer, Pretoria.

Visualisation opened the process to expression of the learners' life-worlds, their primary habitus, which resulted in the uniqueness of each story. The distance between the habitus generated by the child's home, and the habitus of the school, could be reduced (Bourdieu \& Passeron 1990:44). Mastery became a tool of expression, rather than an end in itself. This relation of the processes of mastery to the agency of the learner-writer proved to be generative in that the learners were able to originate extended text.

The project was expensive in terms of time. During the first year the children worked on the production of their books - albeit intermittently - for six months in available 'literacy' time. In the second year, time for writing books was accommodated by clustering some subjects so that the curriculum in Natural Sciences (NS), Economic and Management Sciences (EMS), and Social Sciences (SS) was completed by the end of the third term. The learners were immersed in the vocabulary and procedures of each discipline intensively for a concentrated period of time so that they could acquire and reflect on disciplinary concepts and knowledge without interruptions and distractions caused by constantly 'switching gears'. This strategy accelerated progress in these disciplines and freed time in the final term to produce the books, and the learners had more general knowledge and vocabulary for their stories. For example, Sinawe, who had written a free adaptation of the fable 'The Lion and the Mouse' in Grade 4, chose to use his knowledge of Geography to set his story in Alaska in Grade 5:

Later they [the family] were given a car to drive around in the thick bottle-green forest. They saw tall trees covered with green leaves and even in summer the mountains were still covered in snow.

When they got to a narrow road, they decided to go further by foot. Orian said to himself, "This is boring! My parents are taking pictures of boring animals like birds and fish in the rivers. I want to see exciting animals like deer, moose and bears. I'm going my own way!' (Sinawe, Grade 5)

Tables 1-2 demonstrate that the word counts of all the Grade 4 stories exceeded those stipulated in the curriculum (Department of Basic Education 2011:32). The Grades 5-6 results were similar.

\section{Conclusions}

Two significant interdependent elements, namely time and agency, emerge from the farm school writing project as essential to promoting pedagogical actions that promote conceptual and creative ability in an acquired language. Agency increased as prescribed limits on pacing decreased.

Time was managed flexibly, in response to the pace at which the learners acquired the skills they needed to produce their 
TABLE 2: Schedule of Grade 4 learners' stories.

\begin{tabular}{|c|c|c|c|c|c|c|c|}
\hline Name & Age & Home & Title & Genre and theme & Word count & Home language & Female/male \\
\hline Khanyisa & 11 & farm & Beautiful Yolanda & Anthropomorphic jealousy, acceptance & 273 & isiXhosa & Female \\
\hline Iman & 10 & town & The king of the forest & Anthropomorphic heroism & 257 & isiXhosa & Male \\
\hline Siyamthanda & 10 & farm & A new home & Anthropomorphic Quest for a home & 231 & isiXhosa & Male \\
\hline Siphosethu & 10 & town & Ben's journey & Anthropomorphic Quest for a home & 305 & isiXhosa & Male \\
\hline Christiaan & 11 & farm & The naughty sheep & Anthropomorphic Cautionary tale & 253 & Afrikaans & Male \\
\hline Taznia & 10 & town & The talking tree & Magic realism conservation & 380 & isiXhosa & Female \\
\hline Alison & 10 & farm & Tom and the man-eating shark & Anthropomorphic justice and restitution & 290 & Afrikaans & Female \\
\hline Libongo & 10 & farm & The good worker & Social realism - crime; loyalty & 287 & isiXhosa & Male \\
\hline Sikelelwa & 10 & farm & Finding a better life & Social realism; poverty & 339 & isiXhosa & Female \\
\hline Keitumetse & 10 & town & How the poor family got rich & Social realism - crime; justice & 216 & isiXhosa & Female \\
\hline Frans & 11 & farm & The two best friends & Social realism; conflict, friendship & 266 & isiXhosa & Female \\
\hline Lindokuhle & 11 & farm & Two friends and a new bakkie & Social realism; conflict, friendship & 237 & isiXhosa & Male \\
\hline Akum & 12 & town & A scary night & Cultural symbolism; taboo & 252 & isiXhosa & Male \\
\hline Sanne & 10 & town & My special birthday & Memoir; family, celebration & 269 & isiXhosa & Female \\
\hline Noluvuyo & 10 & farm & Samantha got lost & Realism; lost and found & 229 & isiXhosa & Female \\
\hline
\end{tabular}

'perfect' manuscripts. Agency, expressed in their freedom to choose and illustrate topics, was important in sustaining their motivation to complete the prolonged process. The mediation protocol that required learners to identify their needs and vision for the next step of the process was also an important strategy for affirming agency.

The most important feature of the project however, was the competence of the teachers as mediators, their leadership, and their commitment to seeing it through. In one class, not all the children completed their books in the first year of the project. These learners' drafts showed lack of progress, which indicated lack of mediation and leadership. This disappointing result, fortunately not typical of the outcome of the whole project, confirmed the McKinsey report's assertion that 'the quality of an education system cannot exceed the quality of its teachers' and 'the only way to improve outcomes is to improve instruction' (Mourshed, Chijioke \& Barber 2007:15).

\section{Acknowledgements Competing interests}

The author declares that she has no financial or personal relationships which may have inappropriately influenced her in writing this article.

\section{Authors' contributions}

The author thanks the teachers for their participation in this project and the school management for providing access. The contents and research results reported in this article have been made available to the school and have been verified as correct. All sources have been fully cited and no plagiarism has been committed.

\section{References}

Akbulut, Y., 2007, 'Bilingual acquisition and cognitive development in early childhood: Challenges to the research paradigm', Elementary Education Online 6(3), 422-429.
Benjamin, L., 2006, The basic concepts programme: Mediator's manual, Published and distributed by Dr. Louis Benjamin, Cape Town.

Bourdieu, P. \& Passeron, J.-C., 1990, Reproduction in education, society and culture, 2nd edn., Sage Publications, London.

Calkins, L., Hartman, A. \& White, Z., 2005, One to one: The art of conferring with young writers, Scholastic, Portsmouth.

Canagarajah, A.S., 1999, 'On EFL teachers, awareness, and agency', ELT Journal 53(3), 207-214. http://dx.doi.org/10.1093/elt/53.3.207

Chimbganda, A.B., 2005, 'Profiling the "native speaker" of English: Myths and implications for ESL learning and teaching', Journal for Language Teaching 39(1), 18-33. http://dx.doi.org/10.4314/jlt.v39i1.6046

Collier, V. \& Thomas, W., 2004, 'The astounding effectiveness of dual language education for all', NABE Journal of Research and Practice 2(1), 1-20.

Daly, N., 1999, Jamela's dress, Tafelberg, Cape Town.

Daly, N., 2003a, Once upon a time, Tafelberg, Cape Town.

Daly, N., 2003b, Yebo, Jamela!, Tafelberg, Cape Town.

Department of Basic Education, 2011, Curriculum and assessment policy statement grades 4-6: English Home Language, Government Printer, Pretoria.

Greene, M., 1988, 'What happened to imagination?', in K. Egan \& D. Nadener (eds.), Imagination \& education, Open University Press, Milton Keynes.

Guthrie, J. \& Klauda, S., 2013, 'Engagement and motivational processes in reading', in P. Afflerbach (ed.), Handbook of individual differences in reading, Routledge Publishers, New York.

Howie, S., Van Staden, S., Tshele, M., Dowse, C. \& Zimmerman, L., 2012, 'PIRLS 2011: South African children's reading literacy achievement report', Centre for Evaluation and Assessment, University of Pretoria.

Krashen, S., 1982, 'Principles and practice in second language acquisition', viewed 16 July 2013, from http://www.sdkrashen.com

Lubbe, P., 2000, Bridge to English: Grade 4 learners' book, Molteno Project, Kagiso, Johannesburg.

Lubbe, P., 2004, New bridge to English: Teachers' guide, Molteno Project, Kagiso, Johannesburg.

Moll, L.C. \& Whitmore, K.F., 1993, 'Vygotsky in classroom practice: Moving from individual transmission to social transaction', in E.A. Foreman, N. Minick \&
C.A. Stone (eds.), Contexts for learning: Sociocultural dynamics in children's C.A. Stone (eds.), Contexts for learning: Sociocultural dynan
development, pp. 19-42, Oxford University Press, New York.

Mourshed, M., Chijioke, C. \& Barber, M., 2007, 'How the world's best-performing school systems come out on top: Executive summary', viewed 20 August 2014 from http://www.smhc-cpre.org

Ngugi wa Thiong'o, 1986, Decolonizing the mind, East African Educational Publishers Ltd., Nairobi.

Olshansky, B., 2007, Picturingwriting, National Convention of Teachers of English (NCTE), New York.

Olshansky, B., 2008, The power of pictures: Creating pathways to literacy through art, Jossey-Bass, San Francisco, CA.

Pahl, K., 2007, 'Creativity in events and practices: A lens for understanding children's multimodal texts', Literacy 41(2), 86-92. http://dx.doi.org/10.1111/j.14679345.2007.00462.x

Palinscar, A.S., 1998, 'Social constructivist perspectives on teaching and learning', Annual Review of Psychology 49, 345-375. http://dx.doi.org/10.1146/annurev. psych.49.1.345

Scharer, P. \& Pinnell, G., 2008, Guiding K-3 writers to independence: The new essentials, New York Ohio State University, Literacy Collaborative, Columbus. 